\title{
A Case Study of Use of MKCL SuperCampus in Teaching of Basics of Electronics Engineering to Enhance Classroom Interactions
}

\author{
Preeti Bhamre', Ajit Jagtap ${ }^{2}$ \\ ${ }^{1}$ IT Dept, K.K.Wagh Institute of Engg. Education and Research, Panchavati, Nasik \\ ${ }^{2}$ Maharashtra Knowledge Corporation Limited, SB Road, Pune \\ pdbhamre@kkwagh.edu.in \\ cto@mkcl.org
}

\begin{abstract}
Learning in classes is significantly improved by using ICT tools. This paper presents a case study of teaching a first year engineering subject of Electronics and Telecommunication with rigorous use of ICT tool named MKCL SuperCampus. The tool is used to pose a few questions intermittently during a lecture on students' mobile and provide a real time summary of student responses for carrying out meaningful interactions, thereby leading to enhanced learning.
\end{abstract}

Keywords: ICT, Teaching-Learning, Reflection, Gamification

\section{Introduction}

In any formal educational system, the use of various ICT tools has seen unprecedented growth in the teaching, learning and evaluation process. Classroom teaching still happens to be an inevitable and irreplaceable component of the teaching-learning process. The classroom time is the dedicated time, during which students are expected to be actively engaged. Effective learning can only be ensured if the students understand and apply the content delivered in the classroom through lecture and other learning activities. In an attempt to enable students to absorb

\section{Preeti Bhamre}

IT Dept, K.K.Wagh Institute of Engg. Education and Research, Panchavati, Nasik

pdbhamre@kkwagh.edu.in and understand concepts thoroughly, the classroom environment should be conducive for mutual interactions between students and the teacher. Learning in classrooms improves significantly if there are meaningful interactions between inquisitive learners and experienced teachers.

There is bulk of evidence showing positive associations between classroom interactions and student outcomes. A theoretically based and empirically evidenced framework - Teaching through interactions (TTI) was proposed in [1] to measure teacher-student and student-student pattern of classroom interactions. This framework identified effective classroom practices and emphasized the need of high quality interactions to particularly boost the performance of high risk students. The three main domains identified in [1] for classroom interactions are emotional support, classroom organization and instructional support. TTI also incorporated another dimension of student engagement, to tap the extent to which students are involved in classroom activities.

A learner exhibits passive behaviour in class when he/she sits quietly, listens to the teacher, takes notes or does something else [2]. The active type of classroom behaviour includes questioning, expressing opinions and answering questions posed. The passive and active behaviours are categorized into four types [3] -full integration, participation under specific circumstances, marginal participation and silent observation. In the presented case study, the classroom behaviour of student participation in the learning process was investigated initially. The 
purpose was to identify the students in terms of active or passive classroom participation.

A study of students' participation in classroom and what motivates them to speak out in class has been presented in [4]. Students do not actively participate or become passive in the classroom despite encouragements and use of various teaching methods by the instructors to stimulate active participation from the students. The four major factors which influence students' participation in the classroom arei) Personality of a student ii) Influence of classmates or peers iii) Influence of teacher in the classroom and iv) Environmental factor.

Creation of reflection spots for face-to-face interactions during classroom teaching is the most common method adopted by teachers. They are largely left on their own when it comes to creating opportunities for reflection in their courses for allowing students to think about the concept taught. They typically ask students to engage in written reflection, like solving a problem during class. Yet anyone who has attempted to implement reflection in his or her teaching must have certainly encountered learner resistance. Teachers also have to maintain a distinction between universal supportive interactions across content areas and content specific forms of support aimed at teaching students particular topics [1]. Interactions must be frequent, consistent and also meet certain quality threshold to manifest the positive effects in student outcomes [5]. In another study [6], it has also been shown that high quality classroom interactions are associated with higher levels of teachers' job satisfaction.

Such meaningful interactions can systematically be introduced during teaching with the help of ICT tools. This paper presents a case study of teaching a first year Computer Engineering subject with rigorous use of one such ICT tool named MKCL SuperCampus. The objectives of the study were to understand if the use of ICT tool could help in improving the subject learning by improving attention span of students during lectures and by overcoming inherent reluctance of students to participate in a lecture and to interact with the teacher.

\section{Methodology}

\section{A. Student Questionnaire}

An initial survey was conducted for a class of 63 students of first year Computer Engineering of K. K. Wagh Institute of Engineering Education and Research, Nashik. 54 students have contributed to the initial survey. The survey results highlight typical attention span of students, availability of time for posing questions using this tool, need to break the monotony of long and continuous lectures and the inherent reluctance of students to participate in a lecture to answer the questions asked by a teacher.

Fig. 1 shows the typical attention span of students in a lecture of one hour. The typical attention span of $46(25+21)$ students is between 30 to 45 minutes. This means that a teacher can engage students for 10-15 minutes in an activity to regain their attention. One of the ways could be to pose a few questions intermittently based on the concepts taught in that lecture, using MKCL SuperCampus.

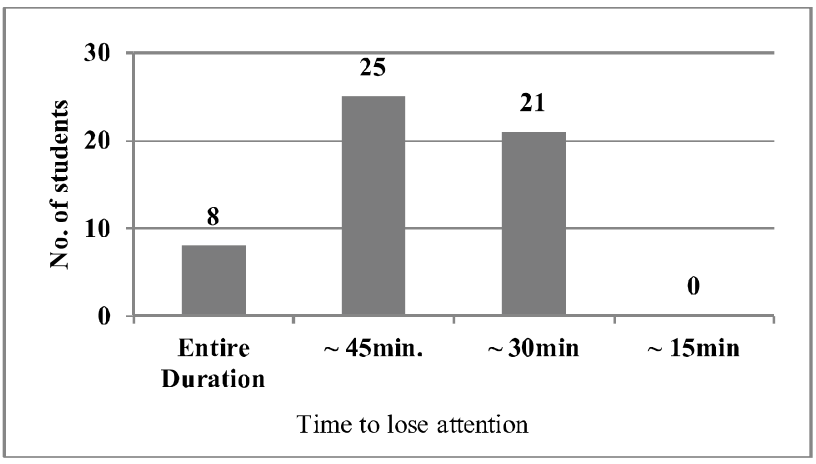

Fig. 1: Attention span of students.

Fig. 2 shows the probable reasons for the loss of attention in a lecture. $42(24+18)$ students think that the reason for the loss of attention is the long and continuous span of teaching. This reiterates that teaching spans should be optimal and a teacher must allow a student in some way to break and also to reconnect quickly.

One of the survey questions was framed to find students' natural and spontaneous initiative to respond to a teacher's question posed during a lecture. The behaviour of fully integrated students i.e. those who actively engage in each class most of the times, were identified as those students who attempted to answer a question even if they were not certain about the correctness of the answer. The second type of behaviour of students with marginal engagement was identified with those who attempted to answer a question only if they were certain about the correctness of the answer. Students with 
circumstantial engagement were those who attempted to answer only when a teacher specifically asked them to answer a question. Silent observers were identified from the category of those students who never attempted to answer a question.

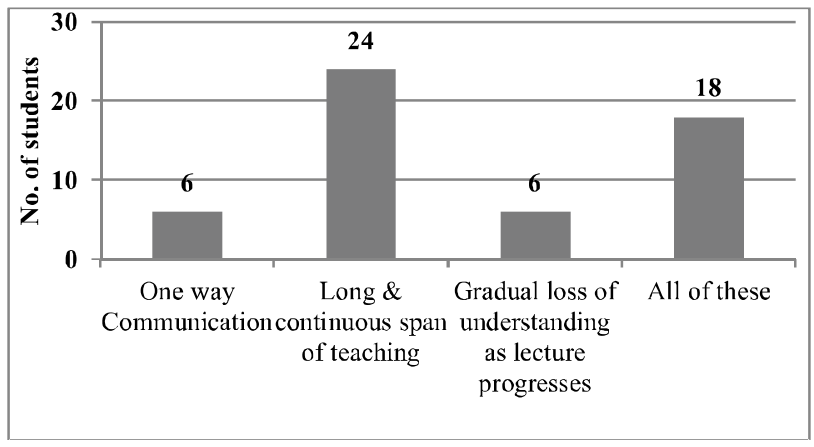

Fig. 2 : Reasons for loss of attention in a lecture.

Fig. 3 shows the students' initiative to respond to a teacher's question posed during a lecture. Only 5 students attempt to answer a question even if they are not certain about the correctness of its answer. Majority of the students are inherently reluctant to answer the questions asked by a teacher during a lecture.

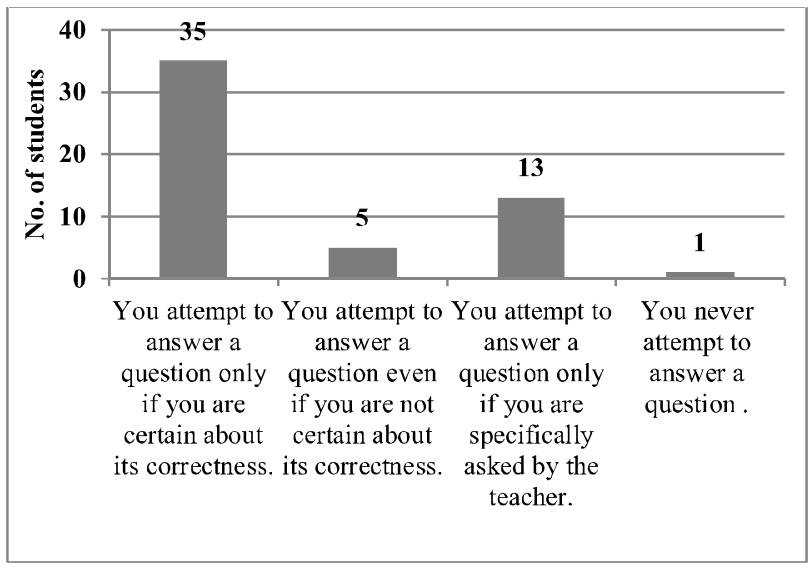

Fig. 3 : Students' initiative to respond to a teacher's question

\section{B. Use of ICT Tool MKCL SuperCampus}

The four significant factors [4] which influence students' participation in class can be addressed effectively by using ICT tools for reflection activities, thereby significantly improving learning in the classes. The adoption of this tool during teaching is also well justified with the results of the initial survey done before the commencement of the course.

The impact of rigorous use of one such ICT tool named MKCL SuperCampus is presented in this case study. The use of this tool was incorporated for the teaching of a first year Computer Engineering course of Basics of Electronics. The MKCL SuperCampus tool was used to pose a few questions intermittently during a lecture on students' mobile. These questions were based on the concepts taught in that lecture/class. A variety of challenging questions, including conceptual distractors were prepared for each topic of the first year engineering subject of Basics of Electronics. These questions were then covered during lectures throughout the course. Such type of classroom environment stimulated learning in every lecture with the use of MKCL SuperCampus tool.

The first and most important factor which affects the students' participation lies in the personality of students. Active learners display personality traits like high confidence levels, high curiosity attitude, an urge to explore new ideas, higher interest to learn more and initiative to participate more in the classroom. Personality traits of passive students are opposite to those of active students and therefore reflect in distinguishing the degree of participation in the classroom. Those students who cannot focus during the lecture, fear of failing in front of classmates, fear of being criticized by teachers for giving incorrect answers and fear of not being able to speak correctly in the medium of instruction like English, are less participative in classrooms. The mobile application of SuperCampus tool allows a passive student to participate and make an attempt to answer the posed questions without any fear, thereby addressing issues of passive personality traits and influence of peer classmates.

The software application collects and segregates the student responses and after each question, a real time statistics are provided to the teacher. This summary is useful in many ways. The second important factor that affects the active participation of students in the classroom, is the encouragement provided by a teacher. An experienced teacher can figure out active learners easily by their spontaneous participation. A teacher usually extends word of appreciation for such learners. Additionally, the projected statistics for every question, displays names of the fastest five students answering correctly. The final summary at the end of all questions displays five top scorers of that lecture. Display of names of top scorers opens a possibility for a teacher to appreciate an otherwise passive student and encourage him/her to participate more and improve further. Individual 
student performance can also be tracked after every lecture to identify poor performers and the teacher can then discuss individually with them. Hence teachers can positively influence students though individual attention and appreciation.

The most important use of the summary is to find the level of understanding of the participating students. In a scenario, where majority students answer incorrectly, the teacher can address the gap in understanding by carrying out more meaningful interactions with students. Thus conceptual learning of a particular topic can be enhanced. With a variety of questions, one can evaluate different levels of learning, which include knowledge, comprehension, application, analysis etc. Hence the nature of questions should go beyond the level of testing information obtained by students during a lecture. Thus framing of questions is the most crucial and important contribution as a teacher in such activities.

ICT tool helps a student to recall information in class, thereby pushing information in long term memory. Students are saved from distractions like Whatsapp alerts, Instagram alerts as their mobile is not connected to the internet. Gamification and excitement in the classroom is possible with the help group competition feature of this tool.

\section{Results and Discussion}

Fig. 4 to Fig. 7 show the snapshots of question wise analysis for four basic topics of the subject under consideration. The incorrect responses illustrate the need to repeat the discussion to clarify the related concept.

The impact of the use of MKCL SuperCampus tool in the teaching of this fundamental subject of first year

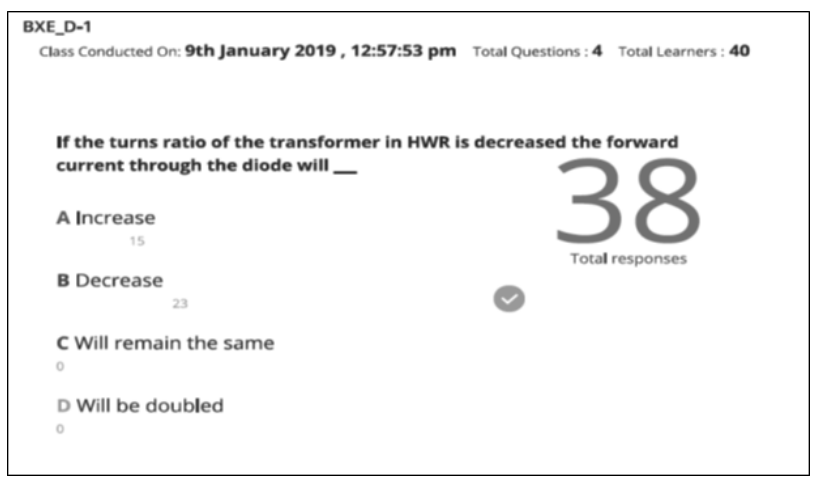

Fig. 4 : Snapshot of Student Reponses for a question of topic 1

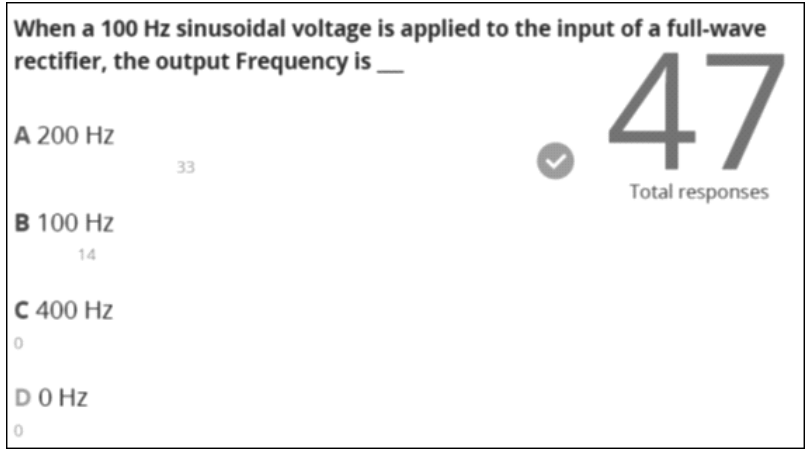

Fig. 5 : Snapshot of Student Reponses for a question of topic 2

engineering was assessed based on comparison of marks obtained by students in online and end semester exams, with the previous batch of students. A total of 194 questions were posed through MKCL SuperCampus throughout the course duration. The effect of participation in class on marks secured in the examination can be compared on the individual basis

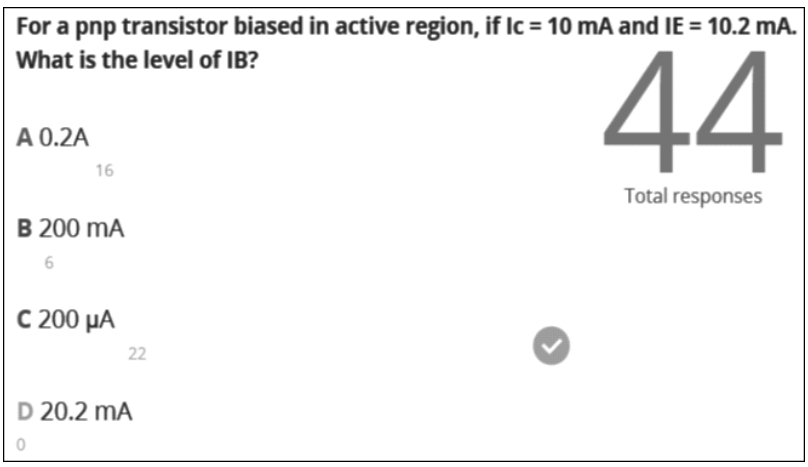

Fig. 6 : Snapshot of Student Reponses for a question of topic 3

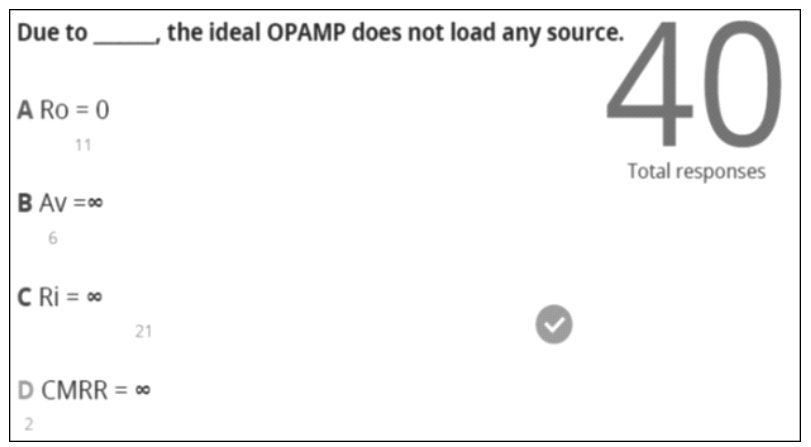

Fig. 7 : Snapshot of Student Reponses for a question of topic 4

only if the student has participated consistently in such an effort. Therefore a comparison of the percentage of correctness in classroom with 
percentage of marks secured in the online examination is made for 24 students who have attempted $75 \%$ questions (i.e. 145 out of 194 ) or more, correctly in class. This comparison is shown in Fig.8. Table 1 shows an improvement in the quality of overall result with $73.4 \%$ students securing top three grades as compared to $65.5 \%$ students securing these grades in the previous academic year.

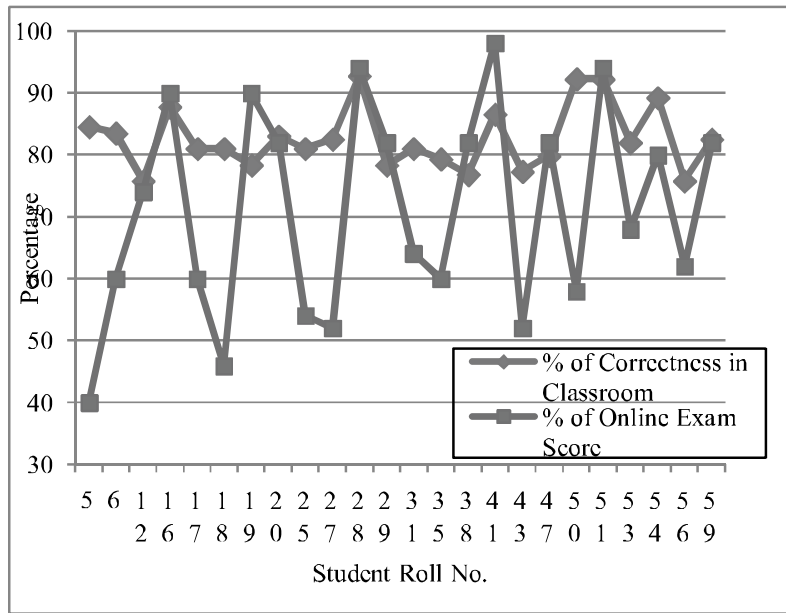

Fig. 8 : Comparison of percentage of correctness in classroom with percentage of marks secured in online examination

Table 1: Comparison of marks obtained by students in online and theory exams, with the marks obtained by students of previous academic year

\begin{tabular}{|l|c|c|}
\hline \multicolumn{1}{|c|}{ Parameter } & \multicolumn{2}{|c|}{ Academic Year } \\
\cline { 2 - 3 } & $\mathbf{2 0 1 7 - 1 8}$ & $\mathbf{2 0 1 8 - 1 9}$ \\
\hline No. of students in class & 58 & 64 \\
\hline $\begin{array}{l}\text { Average Score of entire class for } \\
\text { Online Examination (Out of 50 } \\
\text { marks) }\end{array}$ & 31.21 & 32.78 \\
\hline $\begin{array}{l}\text { Average Score of entire class for } \\
\text { Theory Examination (Out of 50 } \\
\text { marks) }\end{array}$ & 29.42 & 30.3 \\
\hline $\begin{array}{l}\text { Average of Total Score of entire } \\
\text { class (Out of 100 marks) }\end{array}$ & 60.53 & 63.08 \\
\hline $\begin{array}{l}\text { No. students securing } \\
\text { Outstanding (O) Grade }\end{array}$ & 11 & 16 \\
\hline No. of students securing A+ Grade & $18.9 \%)$ & $(25 \%)$ \\
\hline $\begin{array}{l}\text { No. of students securing A Grade } \\
(27.5 \%)\end{array}$ & $\begin{array}{c}11 \\
(21.87 \%)\end{array}$ \\
\hline $\begin{array}{l}\text { Total no. of students securing top } \\
\text { three Grades ( O, A+, A) }\end{array}$ & $\begin{array}{c}18.9 \%) \\
(29.3 \%)\end{array}$ \\
\hline
\end{tabular}

An intermediate survey was also conducted to find the extent to which the tool had helped students in improving their participation in class. Fig. 9 shows

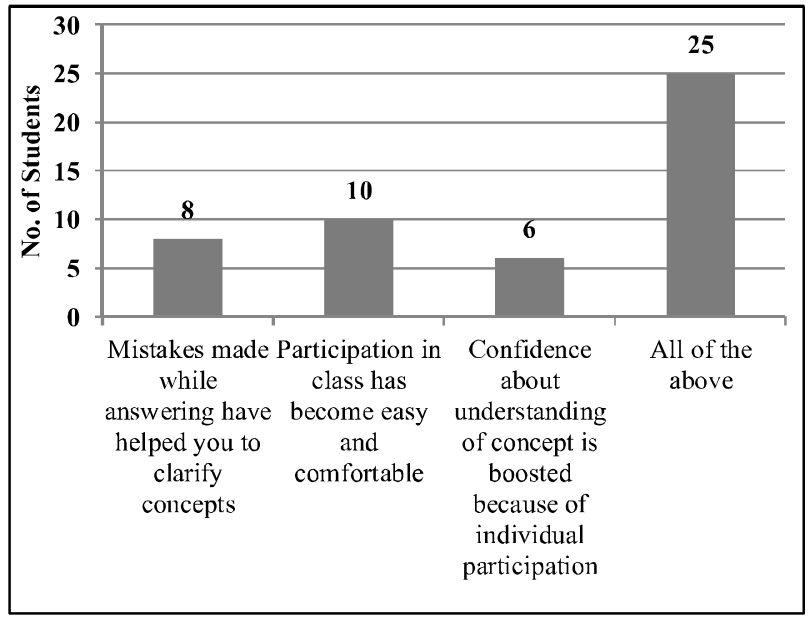

Fig. 9 : Benefits derived by using the ICT tool

that 25 out of 49 respondents expressed that the use of the tool has helped them individually in all three mentioned aspects and the rest of the students admit that it has helped them in some way or the other.

\section{Conclusions}

Based on both, the examination results and the survey outcomes, it can be concluded that use of an ICT tool like MKCL SuperCampus in the teaching of a course of Electronics Engg., has effectively addressed following three issues -

- Improving attention span of students.

- Improving the participation of students in the class.

- Improving the conceptual understanding of students.

\section{Acknowledgement}

We would like to thank Mr. Vivek Sawant for constant support and guidance. We would also like to thank Prof.Nitin Shahane and Dr.Prajakta Baste for providing valuable inputs for this case study.

\section{References}

[1] B.K. Hamre, R.C. Pianta, J.T. Downer, J. Decoster, A.J. Mashburn, S.M. Jones, A. Hamagami (2013), Teaching through interactions: Testing a developmental framework of teacher effectiveness in over 4,000 classrooms, The Elementary School Journal, 113(4), 461-487. 
[2] Bas, G. (2010) Effects of multiple intelligences instruction strategy on students' achievement levels and attitudes towards English lesson, Cypriot Journal of Educational Sciences, 5(3), 167-180.

[3] Liu, J. (2001) Asian students' classroom communication patterns in U.S. universities: an emic perspective, Greenwood Publishing Group Inc., USA.

[4] Abdullah, M.Y., Bakar, N.R.A. and Mahbob, M.H. (2012) Student's participation in classroom: What motivates them to speak up, Elsevier Procedia -
Social and Behavioral Sciences, 51, 516-522.

[5] R.C. Pianta (2016), Classroom processes and teacher-student interaction: Integrations with a developmental psychopathology perspective, D. Chichetti (Ed.), Developmental psychopathology (3rd ed.), vol. 4: Risk, resilience and intervention, Wiley, Hoboken, NJ, 770-814.

[6] Virtanen, T.E., Vaaland, G.S., Ertesvåg, S.K. (2019), Associations between observed patterns of classroom interactions and teacher wellbeing in lower secondary school, Teaching and Teacher Education, 77, 240-252. 